\title{
General theorising and historical specificity: Hodgson on Keynes - CORRIGENDUM
}

Rod O’Donnell

https://doi.org/10.1017/S1744137418000413, Published by Cambridge University Press, March 2019

In the original article, formatting changes introduced errors and inconsistencies in the key equations present on page 12, and between the online and print versions of the article.

The correct formatting for these equations is presented below:

These broad patterns of change and stasis in $Y, \chi$ and $C$ that eliminate any notions of universality are summarised below, with ${ }^{\star}$ indicating constancy.

$\begin{array}{ll}\text { General, expanded form of } C=\chi(Y) & C=\chi^{\prime}\left(Y, O F, I D_{1}, I D_{2}, S F\right) \quad \text { [Keynes's theory] } \\ \text { Short intervals, normal conditions } & C=\chi^{\prime}\left(Y, O F^{*}, I D_{1}^{*}, I D_{2}^{*}, S F^{*}\right) \quad \text { [Keynes's 'law'] } \\ \text { Longer intervals, normal conditions } & C=\chi^{\prime}\left(Y, O F, I D_{1}, I D_{2}^{*}, S F^{*}\right) \\ \text { Abnormal conditions } & C \neq \chi^{\prime}\left(Y, O F, I D_{1}, I D_{2}, S F\right) \\ \text { Stationary state } & C^{*}, Y^{*}, O F^{*}, I D_{1}^{*}, I D_{2}^{*}, S F^{*}\end{array}$

Cite this article: O'Donnell R (2019). General theorising and historical specificity: Hodgson on Keynes - CORRIGENDUM. Journal of Institutional Economics 15, 749-749. https://doi.org/10.1017/S1744137419000298

(c) Millennium Economics Ltd 2019 